S Research Square

\title{
Factors Associated with the Use of Insecticide- Treated Nets: Analysis of the 2018 Burkina Faso Malaria Indicator Survey
}

Mahamadi Tassembedo ( $\square$ tassembedomahamadi@gmail.com )

Institut Africain de Sante Publique https://orcid.org/0000-0001-5961-1998

Soumaila Coulibaly

Centre National de Recherche et de Formation sur le Paludisme

Boukary Ouedraogo

Institut de Formation et de recherche interdisciplinaires en sciences de la santé et de l'éducation

Research

Keywords: Burkina Faso, malaria, insecticide-treated nets, malaria indicator survey

Posted Date: September 2nd, 2020

DOl: https://doi.org/10.21203/rs.3.rs-66868/v1

License: @ (i) This work is licensed under a Creative Commons Attribution 4.0 International License. Read Full License 


\section{Abstract}

Sleep under an ITN reduce contact with mosquitoes through the combination of a physical barrier and an insecticidal effect, which reduces the incidence of malaria. The 2016-2020 Burkina Faso National Malaria Strategic Plan aims to have at least $90 \%$ of the population, $100 \%$ of children under age 5 , and $100 \%$ of pregnant women sleep under an ITN. To help achieve this goal, this analysis examines the factors that are associated with the use of ITN nets by using data from the 2017-18 Burkina Faso Malaria Indicator Survey (MIS). The analysis examines individual, household, and community-level factors associated with ITN usage. According to the 2017-18 Burkina Faso MIS, 58\% of individuals in households that own at least one ITN reported that they slept under an ITN on the night before the survey. The use of ITNs was significantly associated with individual, household, and community-level variables that included age, gender, age of household head, number of sleeping rooms, wealth, malaria prevalence, residence, and region. The results highlight areas of intervention at the individual, household, and community levels that can increase ITN use.

\section{Background}

Malaria is a disease caused by parasites that are transmitted to people though the bites of infected female Anopheles mosquitoes [1]. Malaria is a major cause of mortality and morbidity in developing countries. According to the World Health Organization (WHO), there were 228 million cases of malaria and 405,000 deaths from malaria worldwide in 2018 , with $93 \%$ of cases and $94 \%$ of deaths occurring in the African Region [2].

One of the core malaria interventions recommended by WHO to protect against mosquito bites is the use of insecticide-treated nets (ITNs). Sleeping under an ITN is effective in reducing the incidence of malaria by reducing contact with mosquitoes through the combination of a physical barrier and an insecticidal effect [35]. Across sub-Saharan Africa (SSA), there has been an increased focus on the scale-up and distribution of ITNs with the goal of having every household at risk of malaria transmission and every person within that household protected by an ITN [6, 7]. Countries have achieved high ITN coverage levels by using net distribution channels such as community delivery, routine health services, and outreach activities [8]. This investment in ITN distribution has increased the proportion of people in malaria-endemic areas sleeping under an ITN from $29 \%$ in 2010 to $50 \%$ in 2018 [2].

Studies have shown that the major driver of ITN use is access to an ITN, because a person cannot use an ITN unless one is available [9-11]. However, individual, household, and community-level factors also influence ITN usage. At the individual level, factors that influence net use include age, gender, education, degree of control over household decision-making, ITN preferences, malaria knowledge and beliefs, and risk perception [12-17]. Household-level determinants of ITN include household size, household composition, number of sleeping rooms, and intrahousehold sleeping arrangements [11,14, 18-21]. At the community level, factors such as residence, environmental conditions, and malaria seasonality have also been shown to influence ITN usage [9, $21,22]$.

Burkina Faso uses ITNs as the principal tool for malaria prevention. The 2016-2020 National Malaria Strategic Plan includes three approaches for ensuring that ITNs are available to the entire population: (1) free 
distribution of ITNs via nationwide campaigns, (2) free distribution of ITNs through routine antenatal care and expanded programs on immunization at all public health facilities, and (3) the sale of ITNs by the private sector [23]. In 2011, the National Malaria Control Program, in collaboration with its partners, implemented the first national campaign for the mass distribution of ITNs. This was followed by three other mass distribution campaigns in 2013, 2016, and 2019 [23]. To achieve universal ITN coverage, the national strategy aimed to provide enough ITNs to cover all residents of the household. The indicator that evaluates this strategy is the percentage of households with at least one ITN for every two people who stayed in the household the night before the interview. The percentage of households with at least one ITN for every two persons increased from 19\% in the 2010 Burkina Faso Demographic and Health Survey (DHS) to 33\% in the 2017-18 Burkina Faso Malaria Indicator Survey (MIS). Another focus of malaria prevention in Burkina Faso is the promotion of ITN use throughout the country. The 2016-2020 National Malaria Strategic Plan aims to have at least $90 \%$ of the population, $100 \%$ of children under age 5 , and $100 \%$ of pregnant women in Burkina Faso sleep under an ITN [24].

Burkina Faso is a landlocked Sahel country located in the center of West Africa. Malaria remains a major public health issue and is endemic throughout the country [23]. The percentage of children age 6-59 months who tested positive for malaria by microscopy, according to the $2017-18$ MIS, ranges from $7 \%$ in the Centre Region to 39\% in the Sud Oust Region (see Fig. 1). Malaria is seasonal across the country, with peak malaria season occurring from June through October. In Burkina Faso, the duration of the rainy season varies across the country with variances in seasonal malaria transmission based on geographic zones. In the north, the rainy season can last up to 3 months, while in the central zone it lasts up to 6 months, and in the south, 9 months [23].

Our central research question is to determine the factors associated with the use of ITN nets in the population. This includes identifying high-risk areas in term of malaria prevalence, as well as factors at the individual, household, and community levels.

Studying the factors that determine net use can lead to a better understanding of the actions that can increase net use in the general population and in specific areas of the country. These targeted actions will make it possible to improve the fight against malaria, which is the leading cause of mortality and morbidity in Burkina Faso.

The results of this study will provide important answers on net use, and will inform decisions on distribution campaigns, the development of net replacement strategies, and the development and deployment of tools that include behavior change communication activities.

\section{Materials And Methods}

\subsection{Data}

Data from the Burkina Faso 2017-18 MIS were used in the analysis. The MIS is a household survey of a representative sample of respondents. The MIS collected data on the availability and use of ITNs in households, and several other malaria indicators. 
External data were obtained from the Malaria Atlas Project (MAP) to determine the variable malaria prevalence in the analysis (described below). Since the Burkina Faso 2017-18 MIS collected GPS coordinates of the clusters, we were able to merge the external data with the DHS data at the cluster level.

\subsection{Variables}

\subsubsection{Outcomes variables}

Our dependent variable is a binary variable of whether an individual living in a household that owned at least one ITN had slept under an ITN the night before the survey. In addition, only de facto individuals that lived in households with at least one ITN were included in the analysis. This resulted in a sample size of 27,299 individuals or 27,333 after applying sample weights.

\subsubsection{Independent variables}

The choice of independent variables (or explanatory variables) was based on the data in the literature and was defined at the cluster, household, and individual level. One of the main variables of interest is malaria prevalence in 2015 estimated by the MAP. The variable is defined as the average parasite rate of plasmodium falciparum (PfPR) in children between the ages of 2 and 10 within the $2 \mathrm{~km}$ (urban) or $10 \mathrm{~km}$ (rural) buffer that surrounds the DHS survey cluster location. This variable is used as a proxy to assess the malaria risk areas.

The remaining variables in the analysis include other cluster level variables of region and place of residence (urban/rural), that would also determine risk areas. The household level variables include wealth quintiles, number of household members (1-34-6,7-9,10+), number of sleeping rooms $(0-1,2,3,4$, more than 4 rooms), and age of household head in years (less than 30, 30-39, 40-49, 50-59, and 60+). The individuallevel variables include age in years $(0-10,11-19,20-29,30-39,40-49,50+)$, sex, and relationship to household head (wife/husband, son/daughter, and others).

\subsection{Statistical analysis}

This paper included descriptive analysis of the data, bivariate analysis to assess the association between the outcome and the independent variables, and multivariate logistic models to assess the magnitude of the associations after including controls. Three logistic models were fit to include each of the three cluster-level variables (malaria prevalence, region, and place of residence) separately. This is due to the high association of these three variables with one another. The multivariate models do not include the variables of number of household members and relationship to household head because these were highly correlated with the number of sleeping rooms and age of the individual, respectively.

All analyses considered the survey sampling design and sampling weights, and used Stata version 16.

\section{Results}

\subsection{Characteristics of the study population}


Table 1 summarizes the characteristics of the study population. For the outcome variable, $58 \%$ of the sample reported that they slept under an ITN on the night before the survey. The sample includes a relatively young population with more than half (58\%) of the sample under age 20 . Most were either the son or daughter of the household head (53\%). Most household heads were age 40-49 (27\%) and age 30-39 (26\%). At the household level, most households had two or three rooms ( $34 \%$ and $27 \%$ respectively) and between four to six household members (39\%). The sample was predominantly rural (82\%), from the regions of Centre Ouest (13\%), Boucle du Mouhoun (12\%), and Hauts-Bassins (11\%). In terms of malaria prevalence, according to the 2015 MAP estimates, a quarter lived in areas with a prevalence of $45-60 \%$, with the majority living in areas with a prevalence of $35-45 \%(39 \%)$. Only $9 \%$ of the sample lived in areas with a malaria prevalence of $0-24 \%$. According to the malaria prevalence variable, the total number of individuals is less than the total for the remaining variables. There were some clusters with missing information for this variable and this resulted in 2,478 unweighted individuals with missing values for this indicator. 
Table 1

Description of the de facto sample used in the analysis among households with at least one ITN

\begin{tabular}{|c|c|c|c|}
\hline Variable & $\%$ & 95\% C.I. & $\mathbf{N}$ \\
\hline \multicolumn{4}{|c|}{ Slept under an ITN last night } \\
\hline Yes & 58.4 & {$[56.8,60.0]$} & 15964 \\
\hline No & 41.6 & {$[40.0,43.2]$} & 11369 \\
\hline \multicolumn{4}{|l|}{ Age in years } \\
\hline $0-10$ & 34.6 & {$[33.8,35.5]$} & 9464 \\
\hline $11-19$ & 23.6 & {$[23.0,24.3]$} & 6456 \\
\hline $20-29$ & 13.0 & {$[12.4,13.6]$} & 3539 \\
\hline $30-39$ & 11.7 & {$[11.3,12.2]$} & 3208 \\
\hline $40-49$ & 7.1 & {$[6.8,7.4]$} & 1927 \\
\hline $50+$ & 10.0 & {$[9.4,10.6]$} & 2731 \\
\hline \multicolumn{4}{|c|}{ Sex of household member } \\
\hline Male & 49.1 & {$[48.5,49.8]$} & 13430 \\
\hline Female & 50.9 & {$[50.2,51.5]$} & 13903 \\
\hline \multicolumn{4}{|c|}{ Relationshop to household head } \\
\hline Head & 17.0 & {$[16.6,17.4]$} & 4642 \\
\hline Wife/husband & 18.5 & {$[18.1,18.8]$} & 5045 \\
\hline Son/daughter & 52.6 & {$[51.7,53.6]$} & 14384 \\
\hline others & 11.9 & {$[11.0,12.9]$} & 3256 \\
\hline \multicolumn{4}{|c|}{ Age of household head } \\
\hline Less than 30 & 8.9 & {$[7.9,10.1]$} & 2444 \\
\hline $30-39$ & 25.6 & {$[24.1,27.2]$} & 6991 \\
\hline $40-49$ & 27.3 & {$[25.7,28.9]$} & 7460 \\
\hline $50-59$ & 18.5 & {$[16.9,20.2]$} & 5054 \\
\hline $60+$ & 19.7 & {$[17.6,21.9]$} & 5371 \\
\hline \multicolumn{4}{|c|}{ Number of rooms for sleeping } \\
\hline $0-1$ room & 13.4 & {$[12.2,14.7]$} & 3666 \\
\hline 2 rooms & 33.7 & {$[31.8,35.6]$} & 9181 \\
\hline 3 rooms & 26.7 & {$[24.8,28.7]$} & 7286 \\
\hline
\end{tabular}




\begin{tabular}{|c|c|c|c|}
\hline Variable & $\%$ & 95\% C.I. & $\mathbf{N}$ \\
\hline 4 rooms & 14.7 & {$[13.2,16.4]$} & 4019 \\
\hline More than 4 rooms & 11.5 & {$[9.8,13.4]$} & 3128 \\
\hline \multicolumn{4}{|c|}{ Number of household members } \\
\hline $1-3$ & 9.2 & {$[8.4,10.1]$} & 2512 \\
\hline $4-6$ & 38.6 & {$[36.7,40.6]$} & 10556 \\
\hline $7-9$ & 29.0 & {$[27.3,30.7]$} & 7923 \\
\hline 10 or more & 23.2 & {$[21.0,25.5]$} & 6341 \\
\hline \multicolumn{4}{|l|}{ Wealth quintile } \\
\hline Lowest & 18.3 & {$[16.0,20.7]$} & 4996 \\
\hline Second & 20.1 & {$[18.6,21.6]$} & 5493 \\
\hline Middle & 20.6 & {$[18.9,22.4]$} & 5623 \\
\hline Fourth & 21.2 & {$[19.2,23.5]$} & 5805 \\
\hline Highest & 19.8 & {$[17.6,22.3]$} & 5416 \\
\hline \multicolumn{4}{|l|}{ Malaria Prevalence* } \\
\hline $0-24 \%$ & 9.1 & {$[7.0,11.8]$} & 2270 \\
\hline $25 \%-34 \%$ & 26.9 & {$[21.9,32.4]$} & 6674 \\
\hline $35-44 \%$ & 38.7 & {$[31.9,45.9]$} & 9617 \\
\hline $45-60 \%$ & 25.3 & {$[20.0,31.4]$} & 6284 \\
\hline \multicolumn{4}{|l|}{ Place of residence } \\
\hline Urban & 18.5 & {$[16.2,21.1]$} & 5053 \\
\hline Rural & 81.5 & {$[78.9,83.8]$} & 22280 \\
\hline \multicolumn{4}{|l|}{ Region } \\
\hline Boucle du mouhoun & 12.1 & {$[10.5,13.9]$} & 3310 \\
\hline Cascades & 4.1 & {$[3.3,5.2]$} & 1131 \\
\hline Centre & 8.8 & {$[7.6,10.3]$} & 2411 \\
\hline Centre est & 6.9 & {$[5.5,8.5]$} & 1877 \\
\hline Centre nord & 8.8 & {$[7.4,10.3]$} & 2398 \\
\hline Centre ouest & 12.6 & {$[8.8,17.7]$} & 3438 \\
\hline Centre sud & 3.9 & {$[3.3,4.5]$} & 1055 \\
\hline
\end{tabular}




\begin{tabular}{|llll|}
\hline Variable & $\%$ & $95 \%$ C.I. & N \\
\hline Est & 8.3 & {$[7.3,9.4]$} & 2266 \\
\hline Hauts-bassins & 11.2 & {$[9.6,13.1]$} & 3068 \\
\hline Nord & 9.2 & {$[8.2,10.3]$} & 2513 \\
\hline Plateau central & 4.7 & {$[4.1,5.3]$} & 1280 \\
\hline Sahel & 6.2 & {$[4.8,8.1]$} & 1702 \\
\hline Sud ouest & 3.2 & {$[2.7,3.8]$} & 885 \\
\hline Total & & & 27333 \\
\hline Note: * Due to missing values, the total for this variable is 24,845 \\
\hline
\end{tabular}

\subsection{Bivariate analysis}

Table 2 shows that all independent variables were significantly associated with the outcome. Individuals age 11-19 used ITNs the least (45\%) compared to other age groups. This corresponds with sons and daughters using nets the least (54\%). More females (63\%) slept under ITN nets compared to males (54\%). At the household level, as the number of rooms or the number of household members increase, the use of ITN nets decreases. Households in the highest wealth quintile had the highest ITN use (65\%), with the remaining wealth quintiles having similar rates of use between $56-57 \%$. 
Table 2

Crosstabulation of variables used in the analysis and slept under an ITN last night among households with at least one ITN

\begin{tabular}{|c|c|c|c|}
\hline Variable & $\%$ & 95\% C.I. & p-value \\
\hline Age in years & & & $<0.001$ \\
\hline $0-10$ & 61.2 & {$[59.2,63.2]$} & \\
\hline $11-19$ & 44.9 & {$[42.8,47.0]$} & \\
\hline $20-29$ & 64.2 & {$[61.7,66.6]$} & \\
\hline $30-39$ & 66.8 & {$[63.9,69.5]$} & \\
\hline $40-49$ & 63.6 & {$[60.9,66.2]$} & \\
\hline $50+$ & 59.6 & {$[56.6,62.5]$} & \\
\hline Sex of household member & & & $<0.001$ \\
\hline Male & 53.6 & {$[51.7,55.4]$} & \\
\hline Female & 63.1 & {$[61.3,64.9]$} & \\
\hline Relationship to household head & & & $<0.001$ \\
\hline Head & 62.3 & {$[60.0,64.6]$} & \\
\hline Wife/husband & 74.3 & {$[72.3,76.2]$} & \\
\hline Son/daughter & 53.8 & {$[52.1,55.6]$} & \\
\hline Others & 48.4 & {$[45.1,51.7]$} & \\
\hline Age of household head & & & $<0.001$ \\
\hline Younger than 30 & 72.3 & {$[68.9,75.4]$} & \\
\hline $30-39$ & 63.8 & {$[61.2,66.3]$} & \\
\hline $40-49$ & 57.1 & {$[54.3,59.8]$} & \\
\hline $50-59$ & 55.2 & {$[51.6,58.7]$} & \\
\hline $60+$ & 50.0 & {$[46.4,53.5]$} & \\
\hline Number of rooms for sleeping & & & $<0.001$ \\
\hline $0-1$ room & 71.3 & {$[68.3,74.1]$} & \\
\hline 2 rooms & 63.0 & {$[60.5,65.4]$} & \\
\hline 3 rooms & 55.2 & {$[52.6,57.7]$} & \\
\hline 4 rooms & 51.6 & {$[48.3,54.9]$} & \\
\hline More than 4 rooms & 46.1 & {$[42.0,50.2]$} & \\
\hline Number of household members & & & $<0.001$ \\
\hline
\end{tabular}




\begin{tabular}{|c|c|c|c|}
\hline Variable & $\%$ & 95\% C.I. & p-value \\
\hline $1-3$ & 75.2 & {$[72.0,78.1]$} & \\
\hline $4-6$ & 65.4 & {$[63.2,67.5]$} & \\
\hline $7-9$ & 54.1 & {$[51.2,57.0]$} & \\
\hline 10 or more & 45.6 & {$[42.5,48.7]$} & \\
\hline Wealth quintile & & & 0.001 \\
\hline Lowest & 55.8 & {$[52.7,58.8]$} & \\
\hline Second & 57.2 & {$[54.6,59.6]$} & \\
\hline Middle & 57.4 & {$[54.1,60.6]$} & \\
\hline Fourth & 57.1 & {$[54.1,60.1]$} & \\
\hline Highest & 64.5 & {$[60.9,68.0]$} & \\
\hline Malaria prevalence* & & & 0.011 \\
\hline $0-24 \%$ & 67.3 & {$[61.8,72.4]$} & \\
\hline $25-34 \%$ & 57.4 & {$[54.2,60.6]$} & \\
\hline $35-44 \%$ & 55.8 & {$[53.1,58.5]$} & \\
\hline $45-60 \%$ & 59.2 & {$[54.8,63.5]$} & \\
\hline Place of residence & & & $<0.001$ \\
\hline Urban & 66.1 & {$[62.8,69.3]$} & \\
\hline Rural & 56.7 & {$[54.8,58.5]$} & \\
\hline Region & & & $<0.001$ \\
\hline Boucle du Mouhoun & 58.9 & {$[53.8,63.8]$} & \\
\hline Cascades & 69.9 & {$[65.8,73.7]$} & \\
\hline Centre & 69.1 & {$[63.9,73.9]$} & \\
\hline Centre Est & 62.6 & {$[57.2,67.7]$} & \\
\hline Centre Nord & 63.4 & {$[60.5,66.1]$} & \\
\hline Centre Ouest & 50.7 & {$[47.3,54.0]$} & \\
\hline Centre Sud & 60.8 & {$[53.3,67.7]$} & \\
\hline Est & 61.0 & {$[55.8,66.0]$} & \\
\hline Hauts-Bassins & 58.3 & {$[51.2,65.0]$} & \\
\hline Nord & 61.6 & {$[56.7,66.3]$} & \\
\hline
\end{tabular}




\begin{tabular}{|c|c|c|c|}
\hline Variable & $\%$ & 95\% C.I. & $\mathrm{p}$-value \\
\hline Plateau Central & 53.4 & {$[46.6,60.2]$} & \\
\hline Sahel & 39.8 & {$[34.5,45.3]$} & \\
\hline Sud Ouest & 45.4 & {$[40.2,50.7]$} & \\
\hline
\end{tabular}

Use of ITN nets was higher in urban areas (66\%) compared to rural areas (57\%). Use of ITNs was also the highest in the Cascades and Centre regions (both approximately 70\%) and the lowest in the Sahel Region (39\%). The use of ITN nets was also highest in areas that had the lowest malaria prevalence (67\%), compared to $59 \%$ that used ITN nets in the areas of highest malaria prevalence.

The relationship between malaria prevalence, region, and place of residence was also examined. Table 3 shows that region and place of residence were both significantly associated with malaria prevalence. Areas of low malaria prevalence were more urban, with $37 \%$ of urban areas having a malaria prevalence of $0-24 \%$ compared to only $2 \%$ of rural areas with that prevalence. In addition, $84 \%$ of the Centre Region, which is highly urban, had a malaria prevalence of $0-24 \%$. In contrast, $72 \%$ of the Hauts-Bassins Region was in the highest malaria prevalence category of $45-60 \%$. This was followed by Boucle du Mouhoun (57\%), Centre Nord (46\%), and Nord (42\%). 
Table 3

Crosstabulation of malaria prevalence with region and place of residence among households with at least one ITN

\begin{tabular}{|c|c|c|c|c|c|c|c|c|c|}
\hline \multirow[b]{3}{*}{ Variable } & \multicolumn{8}{|c|}{ Malaria prevalence } & \multirow{3}{*}{$\begin{array}{l}\mathrm{p}- \\
\text { value }\end{array}$} \\
\hline & \multicolumn{2}{|c|}{$0-24 \%$} & \multicolumn{2}{|c|}{$25-34 \%$} & \multicolumn{2}{|c|}{$35-44 \%$} & \multicolumn{2}{|c|}{$45-60 \%$} & \\
\hline & $\%$ & 95\% C.I. & $\%$ & 95\% C.I. & $\%$ & 95\% C.I. & $\%$ & 95\% C.I. & \\
\hline $\begin{array}{l}\text { Place of } \\
\text { residence }\end{array}$ & & & & & & & & & $\begin{array}{l}< \\
0.001\end{array}$ \\
\hline Urban & 37.4 & {$[29.7,45.8]$} & 23.6 & {$[16.9,31.8]$} & 31.8 & {$[22.4,43.0]$} & 7.2 & {$[1.9,23.6]$} & \\
\hline Rural & 2.4 & {$[1.1,4.9]$} & 27.6 & {$[21.9,34.3]$} & 40.4 & {$[32.4,48.8]$} & 29.6 & {$[23.4,36.8]$} & \\
\hline Region & & & & & & & & & $\begin{array}{l}< \\
0.001\end{array}$ \\
\hline $\begin{array}{l}\text { Boucle } \\
\text { du } \\
\text { Mouhoun }\end{array}$ & 0.0 & & 0.0 & & 43.0 & {$[21.3,67.8]$} & 57.0 & {$[32.2,78.7]$} & \\
\hline Cascades & 0.0 & & 59.7 & {$[38.0,78.2]$} & 37.0 & {$[18.9,59.7]$} & 3.3 & {$[0.4,21.4]$} & \\
\hline Centre & 83.7 & {$[59.3,94.8]$} & 16.3 & {$[5.2,40.7]$} & 0.0 & & 0.0 & & \\
\hline $\begin{array}{l}\text { Centre } \\
\text { Est }\end{array}$ & 0.0 & & 100.0 & & 0.0 & & 0.0 & & \\
\hline $\begin{array}{l}\text { Centre } \\
\text { Nord }\end{array}$ & 0.0 & & 20.2 & {$[6.1,49.6]$} & 33.7 & {$[14.4,60.7]$} & 46.1 & {$[21.4,72.8]$} & \\
\hline $\begin{array}{l}\text { Centre } \\
\text { Ouest }\end{array}$ & 0.0 & & 15.1 & {$[5.3,36.4]$} & 84.9 & {$[63.6,94.7]$} & 0.0 & & \\
\hline $\begin{array}{l}\text { Centre } \\
\text { Sud }\end{array}$ & 33.9 & {$[14.9,60.0]$} & 50.7 & {$[27.8,73.3]$} & 15.4 & {$[5.2,37.6]$} & 0.0 & & \\
\hline Est & 3.3 & {$[0.4,21.0]$} & 34.8 & {$[17.3,57.8]$} & 55.7 & {$[32.6,76.6]$} & 6.1 & {$[0.8,34.4]$} & \\
\hline $\begin{array}{l}\text { Hauts- } \\
\text { Bassins }\end{array}$ & 0.0 & & 0.0 & & 28.4 & {$[15.0,47.1]$} & 71.6 & {$[52.9,85.0]$} & \\
\hline Nord & 0.0 & & 8.8 & {$[1.2,43.5]$} & 49.0 & {$[28.7,69.6]$} & 42.2 & {$[22.9,64.3]$} & \\
\hline $\begin{array}{l}\text { Plateau } \\
\text { Central }\end{array}$ & 6.2 & {$[0.8,35.1]$} & 93.8 & {$[64.9,99.2]$} & 0.0 & & 0.0 & & \\
\hline Sahel & 0.0 & & 52.6 & {$[21.1,82.2]$} & 27.6 & {$[8.1,62.3]$} & 19.7 & {$[3.4,63.5]$} & \\
\hline $\begin{array}{l}\text { Sud } \\
\text { Ouest }\end{array}$ & 0.0 & & 0.0 & & 70.5 & {$[43.9,88.0]$} & 29.5 & {$[12.0,56.1]$} & \\
\hline Total & 9.1 & {$[7.0,11.8]$} & 26.9 & {$[21.9,32.4]$} & 38.7 & {$[31.9,45.9]$} & 25.3 & {$[20.0,31.4]$} & \\
\hline
\end{tabular}


Table 4 summarizes the adjusted odds ratios (AOR) estimates from the three models fit for the outcome variable. Model 1 includes the malaria prevalence variable without region or place of residence. Model 2 includes the region variables without the malaria prevalence and place of residence variables, and Model 3 the place of residence variable without the malaria prevalence and region variables. All models had the same controls. 
Table 4

Adjusted odds ratios for slept under an ITN last night among households with at least one ITN

\begin{tabular}{|c|c|c|c|c|c|c|}
\hline & Model 1 & & Model 2 & & Model 3 & \\
\hline Variable & AOR & 95\% C.I. & AOR & 95\% C.I. & AOR & 95\% C.I. \\
\hline \multicolumn{7}{|l|}{ Age in years } \\
\hline 0-10 (Ref.) & 1 & & & & & \\
\hline $11-19$ & $0.5^{\star \star \star}$ & $0.5-0.6$ & $0.5^{\star \star \star}$ & $0.5-0.6$ & $0.5^{\star \star \star}$ & $0.5-0.6$ \\
\hline $20-29$ & $0.9 *$ & $0.8-1.0$ & $0.9 *$ & $0.8-1.0$ & $0.9 * \star$ & $0.8-1.0$ \\
\hline 30-39 & $1.1^{*}$ & $1.0-1.3$ & $1.1^{*}$ & $1.0-1.3$ & $1.1^{*}$ & $1.0-1.3$ \\
\hline $40-49$ & $1.2^{\star \star \star}$ & $1.1-1.4$ & $1.2^{\star \star \star}$ & $1.1-1.4$ & $1.2^{\star \star \star}$ & $1.1-1.4$ \\
\hline $50+$ & 1.1 & $1.0-1.3$ & 1.1 & $1.0-1.3$ & 1.1 & $1.0-1.3$ \\
\hline \multicolumn{7}{|c|}{ Sex of household member } \\
\hline Male (Ref.) & 1 & & 1 & & 1 & \\
\hline Female & $1.5^{\star \star \star}$ & $1.4-1.6$ & $1.5^{\star \star \star}$ & $1.4-1.6$ & $1.5^{\star \star \star}$ & $1.4-1.6$ \\
\hline \multicolumn{7}{|c|}{ Age of household head } \\
\hline Less than 30 (Ref.) & 1 & & 1 & & 1 & \\
\hline 30-39 & $0.7 * *$ & $0.6-0.9$ & $0.7^{\star \star}$ & $0.6-0.9$ & $0.7 * \star$ & $0.6-0.9$ \\
\hline $40-49$ & $0.6^{\star \star \star}$ & $0.5-0.8$ & $0.7^{\star \star \star}$ & $0.6-0.9$ & $0.6^{\star \star \star}$ & $0.5-0.8$ \\
\hline $50-59$ & $0.7 * \star$ & $0.5-0.9$ & $0.7^{\star}$ & $0.6-0.9$ & $0.7 * \star$ & $0.5-0.9$ \\
\hline $60+$ & $0.6^{\star \star \star}$ & $0.4-0.7$ & $0.6 * \star \star$ & $0.5-0.7$ & $0.6^{\star \star \star}$ & $0.4-0.7$ \\
\hline \multicolumn{7}{|c|}{ Number of rooms for sleeping } \\
\hline 0-1 room (Ref.) & 1 & & 1 & & 1 & \\
\hline 2 rooms & $0.7 * \star$ & $0.6-0.9$ & $0.7^{\star \star \star}$ & $0.6-0.8$ & $0.8^{*}$ & $0.6-0.9$ \\
\hline 3 rooms & $0.6^{\star \star \star}$ & $0.5-0.7$ & $0.5^{\star \star \star}$ & $0.4-0.6$ & $0.6^{\star \star \star}$ & $0.5-0.7$ \\
\hline 4 rooms & $0.5^{\star \star \star}$ & $0.4-0.7$ & $0.4^{\star \star \star}$ & $0.3-0.6$ & $0.5^{\star \star \star}$ & $0.4-0.7$ \\
\hline More than 4 rooms & $0.4^{\star \star \star}$ & $0.3-0.5$ & $0.4^{\star \star \star}$ & $0.3-0.5$ & $0.4^{\star \star \star}$ & $0.3-0.6$ \\
\hline \multicolumn{7}{|l|}{ Wealth quintile } \\
\hline Lowest (Ref.) & 1 & & 1 & & 1 & \\
\hline Second & 1.1 & $1.0-1.3$ & 1.0 & $0.9-1.2$ & 1.2 & $1.0-1.4$ \\
\hline Middle & $1.3^{*}$ & $1.0-1.5$ & 1.2 & $1.0-1.4$ & $1.3^{\star \star}$ & $1.1-1.6$ \\
\hline Fourth & $1.3^{\star \star}$ & $1.1-1.6$ & $1.2^{\star}$ & $1.0-1.4$ & $1.3^{\star \star}$ & $1.1-1.6$ \\
\hline
\end{tabular}




\begin{tabular}{|c|c|c|c|c|c|c|}
\hline \multirow[b]{2}{*}{ Highest } & \multicolumn{2}{|c|}{ Model 1} & \multicolumn{2}{|l|}{ Model 2} & \multicolumn{2}{|c|}{ Model 3} \\
\hline & $1.6^{\star \star \star}$ & $1.2-2.0$ & $1.4^{\star \star}$ & $1.1-1.7$ & $1.4^{\star \star}$ & $1.1-1.8$ \\
\hline \multicolumn{7}{|l|}{ Malaria Prevalence } \\
\hline $0-24 \%$ (Ref.) & 1 & & - & - & - & - \\
\hline $25 \%-34 \%$ & $0.7^{\star}$ & $0.5-1.0$ & - & - & - & - \\
\hline $35-44 \%$ & $0.7^{*}$ & $0.5-0.9$ & - & - & - & - \\
\hline $45-60 \%$ & 0.8 & $0.6-1.2$ & - & - & - & - \\
\hline \multicolumn{7}{|l|}{ Place of residence } \\
\hline Urban (Ref.) & - & - & - & - & 1 & \\
\hline Rural & - & - & - & - & $0.8^{*}$ & $0.6-1.0$ \\
\hline \multicolumn{7}{|l|}{ Region } \\
\hline Boucle du mouhoun & - & - & $0.7^{\star}$ & $0.5-1.0$ & - & - \\
\hline Cascades & - & - & 0.9 & $0.7-1.3$ & - & - \\
\hline Centre (Ref.) & - & - & 1 & & - & - \\
\hline Centre est & - & - & 0.7 & $0.5-1.0$ & - & - \\
\hline Centre nord & - & - & 0.9 & $0.6-1.2$ & - & - \\
\hline Centre ouest & - & - & $0.5^{\star \star \star}$ & $0.4-0.7$ & - & - \\
\hline Centre sud & - & - & 0.8 & $0.5-1.2$ & - & - \\
\hline Est & - & - & 0.8 & $0.6-1.2$ & - & - \\
\hline Hauts-bassins & - & - & $0.6^{*}$ & $0.4-0.9$ & - & - \\
\hline Nord & - & - & 0.8 & $0.6-1.1$ & - & - \\
\hline Plateau central & - & - & $0.5^{\star \star}$ & $0.3-0.8$ & - & - \\
\hline Sahel & - & - & $0.3^{\star \star \star}$ & $0.2-0.4$ & - & - \\
\hline Sud ouest & - & - & $0.4^{\star \star \star}$ & $0.3-0.5$ & - & - \\
\hline Note: ${ }^{\star} p<0.05, * * p<$ & $<0.001$ & & & & & \\
\hline
\end{tabular}

At the individual level, individuals age 11-19 had $50 \%$ lower odds of using an ITN compared to individuals age $0-10$ in all three models. Those age $40-49$ had $20 \%$ greater odds of ITN use compared to individuals age $0-10$. Females had $50 \%$ greater odds of using ITNs compared to males in all three models.

At the household level, heads of household age 30 and above had between $30-40 \%$ lower odds of using an ITN compared to heads of households younger than age 30. The odds of ITN use decrease with an increasing number of rooms. Households that have more than four rooms had $60 \%$ lower odds of ITN use compared to 
households with 0-1 rooms in all three models. In general, we find that the odds of ITN use increases with increasing wealth quintile.

In Model 1, the odds of ITN use were significantly lower in areas with 25\%-34\% and 35\%-44\% malaria prevalence compared to areas with $0-24 \%$ prevalence (30\% lower odds for both categories). In addition, there was no significant difference in ITN use between areas with the highest malaria prevalence of $45 \%-60 \%$ and areas with the lowest prevalence of $0 \%-24 \%$.

In Model 2, individuals who live in the regions of Boucle du Mouhoun, Centre Ouest, Hauts-Bassins, Plateau Central, Sahel, and Sud Ouest had significantly lower odds of ITN use compared to the Centre Region. The highest disparities were found in Sahel and Sud Ouest with 70\% and 60\% lower odds, respectively, compared to the Centre Region.

In Model 3, individuals who live in rural areas had 20\% lower odds of sleeping under an ITN net the night before the survey compared to individuals who live in urban areas.

\section{Discussion}

Data from the Burkina Faso 2017-18 MIS were obtained from The DHS Program. This analysis evaluated factors that influence ITN use in Burkina Faso. Overall, 58\% of individuals slept under an ITN in households that own at least one ITN. This proportion can be explained by the fact that the period of the survey (period of low malaria transmission) does not allow for a better appreciation of the actual use of ITNs by households. Other factors can also influence net use such as the absence of a net, use of a fan, and use of repellents or insecticide by households during the same night.

The results showed differences in the use of nets at the individual, household, and community levels. At the individual level, older children had reduced odds of using an ITN as compared to the youngest children in the household. Females were also more likely to sleep under an ITN as compared to males. This corroborates previous research that found that most households in SSA prioritize ITN use in young children (children under

age 5) and pregnant women of reproductive age. In these households, children share sleeping spaces with their mothers or with other female siblings $[11,20]$. Older children are not priorities for nets, especially when a household does not have enough nets for all members in the household.

At the household level, the number of rooms for sleeping and wealth quintile were significantly associated with ITN use. The odds of ITN use decrease with an increasing number of rooms in households. This aligns with previous studies that found the main reasons for nonuse of ITNs to be lack of access to a net and not having enough nets for all household members within the household [10,15,25]. Typically, the bigger the household with more sleeping spaces, the more people live in the household. This analysis only examined ITN use in households with at least one ITN, and did not examine if the household had adequate nets for all the household members. Future analysis will examine ITN access as it relates to ITN use in Burkina Faso.

When examining ITN usage by community level, ITN use was significantly associated with malaria prevalence, residence, and region. While these factors are interrelated, it does highlight that there are places within Burkina Faso that should be prioritized for future social behavior messaging focused on increasing ITN usage. Previous studies have shown that over time, the Centre Region has consistently displayed high ITN usage, 
most likely reflective of the population in the Centre Region, which is concentrated in urban areas (Ouagadougou) [26]. This analysis aligns with prior research that found rural areas to have lower odds of ITN use as compared to urban areas, and all other regions in the country having lower odds of ITN usage as compared to the Centre Region. Finally, ITN use was significantly lower in areas with $25-34 \%$ and $35-44 \%$ malaria prevalence compared to areas with $0-24 \%$ prevalence. In addition, there was no significant difference in ITN use between areas with the highest malaria prevalence (45-60\%) and areas with the lowest malaria prevalence $(0-24 \%)$. This suggests that future malaria prevention methods should not prioritize low-burden urban areas, but instead focus on messaging in more rural areas of mid- or high-level malaria prevalence.

There are several limitations to this study. First, the study period coincides with the low malaria transmission period in Burkina Faso. Past studies have shown that ITN use is highly influenced by variations in rainfall and malaria seasonality [22,27]. This analysis controlled for malaria endemicity, but was unable to account for variations in rainfall and malaria seasonality across the country. Accurately controlling for patterns in seasonal malaria transmission requires access to more microlevel data, which were unavailable at the time of analysis. Future analysis should examine this in more detail. Secondly, this analysis did not control for intrahousehold characteristics that dictate ITN use. The intrahousehold characteristics of household members influences net allocation in households with too few nets to cover all household members [28]. Finally, the data analyzed are cross-sectional in nature and thus do not permit causal inferences.

\section{Conclusion}

Use of ITNs represents one of the most viable options for reducing malaria-related morbidity and mortality. The results of this study have highlighted areas of intervention at the individual, household, and community level that can increase ITN use. It is important to consider these factors in the national net distribution and awareness-raising strategies for malaria control in Burkina Faso. As the country works to eliminate malaria, the results of this study can help reduce the incidence of malaria and prevent its resurgence. In addition, periodic evaluation of malaria reduction strategies will provide a framework for reliably assessing the effectiveness of these interventions and informing future strategies that can eliminate malaria.

\section{Declarations}

Ethics approval and consent to participate: We use secondary data from DHS repository for our analysis. Approval and consent to participate were previously obtained for the study.

Consent for publication: there are no issues for publication

Availability of data and material: Data and materials are available on DHS site: https://dhsprogram.com/data/available-datasets.cfm for MIS Burkina Faso 2017-18

Competing interests: there are no competing interest for this study.

Author Contributions: Design and perform the methodical analysis, M.T; conceptualization, clean data, merge data, data analysis, S.C; guide conceptualization and data analysis, B.O. All authors contributed to the interpretation of the results, reviewed critically, read and approve the final manuscript. 
Funding: This study was implemented with support from the United States Agency for International Development (USAID) through The DHS Program (\#AID-OAA-C-13-00095).

Acknowledgments: We are very grateful to USAID for funding our research project. We acknowledge and thank the high-quality team of the ICF International and the DHS Fellows Program. Particular thanks to Shireen Assaf for her availability and precious time for giving us advice, and her commitment and valuable contributions that helped us produce a quality work. We are grateful for the extensive review by Cameron Taylor, and appreciate all the hard work and time devoted to this publication. We are grateful to our institution, Institut de Formation et de Recherche Interdisciplinaires en Sciences de la Santé et de l'Education (IFRISSE), whose support made this paper possible.

Conflicts of Interest: The authors declare no conflict of interest.

\section{References}

1. World Health Organization. Fact sheet about Malaria [Internet]. 2020 [cited 2020 Aug 20]. Available from: https://www.who.int/news-room/fact-sheets/detail/malaria.

2. World Health Organization. World malaria report 2019 [Internet]. 2019 p. 232. Available from: https://www.who.int/publications-detail-redirect/9789241565721.

3. Fegan GW, Noor AM, Akhwale WS, Cousens S, Snow RW. Effect of expanded insecticide-treated bednet coverage on child survival in rural Kenya: a longitudinal study. The Lancet. 2007 Sep;22(9592):1035-9. 370 .

4. Habluetzel A, Diallo DA, Esposito F, Lamizana L, Pagnonl F, Lengeler C, et al. Do insecticide-treated curtains reduce all-cause child mortality in Burkina Faso? Tropical Med Int Health. 1997;2(9):855-62.

5. Lengeler C. Insecticide-treated bed nets and curtains for preventing malaria. Cochrane Database Syst Rev. 2004;(2):CD000363.

6. Kilian A, Wijayanandana N, Ssekitoleeko J. Review of delivery strategies for insecticide treated mosquito nets: are we ready for the next phase of malaria control efforts? TropIKA.net. 2010 Mar;1(1):0-0.

7. Willey BA, Paintain LS, Mangham L, Car J, Schellenberg JA. Strategies for delivering insecticide-treated nets at scale for malaria control: a systematic review. Bull World Health Organ. 2012 Sep 1;90(9):672$684 \mathrm{E}$.

8. Taylor C, Florey L, Ye Y. Equity trends in ownership of insecticide-treated nets in 19 sub-Saharan African countries. Bull World Health Organ. 2017 May;95(5)(1):322-32.

9. Graves PM, Ngondi JM, Hwang J, Getachew A, Gebre T, Mosher AW, et al. Factors associated with mosquito net use by individuals in households owning nets in Ethiopia. Malaria Journal. 2011 Dec;13(1):354. 10(.

10. Koenker H, Kilian A. Recalculating the Net Use Gap: A Multi-Country Comparison of ITN Use versus ITN Access. PLOS ONE. 2014 May 21;9(5):e97496.

11. Olapeju B, Choiriyyah I, Lynch M, Acosta A, Blaufuss S, Filemyr E, et al. Age and gender trends in insecticide-treated net use in sub-Saharan Africa: a multi-country analysis. Malaria Journal. 2018 Nov;14(1):423. 17(. 
12. Ca B, Mc M. Intra-household mosquito net use in Ethiopia, Ghana, Mali, Nigeria, Senegal, and Zambia: are nets being used? Who in the household uses them? Am J Trop Med Hyg. 2007 Nov;77(5)(1):963-71.

13. Chuma J, Okungu V, Ntwiga J, Molyneux C. Towards achieving Abuja targets: identifying and addressing barriers to access and use of insecticides treated nets among the poorest populations in Kenya. BMC Public Health. 2010 Mar 16;10(1):137.

14. Dunn CE, Le Mare A, Makungu C. Malaria risk behaviours, socio-cultural practices and rural livelihoods in southern Tanzania: Implications for bednet usage. Social Science \& Medicine. 2011 Feb 1;72(3):408-17.

15. Eisele TP, Keating J, Littrell M, Larsen D, Macintyre K. Assessment of Insecticide-Treated Bednet Use Among Children and Pregnant Women Across 15 Countries Using Standardized National Surveys. The American Journal of Tropical Medicine and Hygiene. 2009 Feb 1;80(2):209-14.

16. Hwang J, Graves PM, Jima D, Reithinger R, Kachur SP. Knowledge of Malaria and Its Association with Malaria-Related Behaviors-Results from the Malaria Indicator Survey, Ethiopia, 2007. PLoS One [Internet]. 2010 Jul 21 [cited 2020 Aug 20];5(7). Available from: https://www.ncbi.nlm.nih.gov/pmc/articles/PMC2908133/.

17. Koenker H, Yukich JO. Effect of user preferences on ITN use: a review of literature and data. Malaria Journal. 2017 Jun;1(1):233. 16(.

18. Iwashita H, Dida G, Futami K, Sonye G, Kaneko S, Horio M, et al. Sleeping arrangement and house structure affect bed net use in villages along Lake Victoria. Malaria Journal. 2010 Jun;22(1):176. 9(.

19. Keating J, Macintyre K, Mbogo CM, Githure JI, Beier JC. Self-reported malaria and mosquito avoidance in relation to household risk factors in a kenyan coastal city. J Biosoc Sci. 2005 Nov;37(6):761-71.

20. Toé LP, Skovmand O, Dabiré KR, Diabaté A, Diallo Y, Guiguemdé TR, et al. Decreased motivation in the use of insecticide-treated nets in a malaria endemic area in Burkina Faso. Malar J. 2009 Jul;29:8:175.

21. Wiseman V, Scott A, McElroy B, Conteh L, Stevens W. Determinants of Bed Net Use in the Gambia: Implications for Malaria Control. Am J Trop Med Hyg. 2007 Jun;1:76:830-6.

22. Koenker H, Taylor C, Burgert-Brucker CR, Thwing J, Fish T, Kilian A. Quantifying Seasonal Variation in Insecticide-Treated Net Use among Those with Access. The American Journal of Tropical Medicine and Hygiene. 2019 Aug 7;101(2):371-82.

23. U.S. Agency for International Development (USAID). President's Malaria Initiative: Burkina Faso - Malaria Operational Plan [Internet]. Burkina Faso; 2019 p. 51. Available from: https://reliefweb.int/report/burkinafaso/president-s-malaria-initiative-burkina-faso-malaria-operational-plan-fy-2019.

24. Ministere de la Santé. Plan Stratégique National 2016-2020. 2016;p. 138. Available from http://onspsante.bf/sites/default/files/publications/166/PSN\%20\%20\%20\%20\%2020162020_Paludisme_20_02_2017.pdf.

25. Hetzel MW, Gideon G, Lote N, Makita L, Siba PM, Mueller I. Ownership and usage of mosquito nets after four years of large-scale free distribution in Papua New Guinea. Malaria Journal. 2012 Jun;10(1):192. 11(.

26. Samadoulougou S, Pearcy M, Yé Y, Kirakoya-Samadoulougou F. Progress in coverage of bed net ownership and use in Burkina Faso 2003-2014: evidence from population-based surveys. Malaria Journal. 2017 Jul;28(1):302. 16(. 
27. Ouedraogo B, Inoue $Y$, Kambiré A, Sallah K, Dieng S, Tine R, et al. Spatio-temporal dynamic of malaria in Ouagadougou, Burkina Faso, 2011-2015. Malar J. 2018 Dec;17(1):138.

28. Lam Y, Harvey SA, Monroe A, Muhangi D, Loll D, Kabali AT, et al. Decision-making on intra-household allocation of bed nets in Uganda: do households prioritize the most vulnerable members? Malaria Journal. 2014 May;17(1):183. 13(.

\section{Figures}

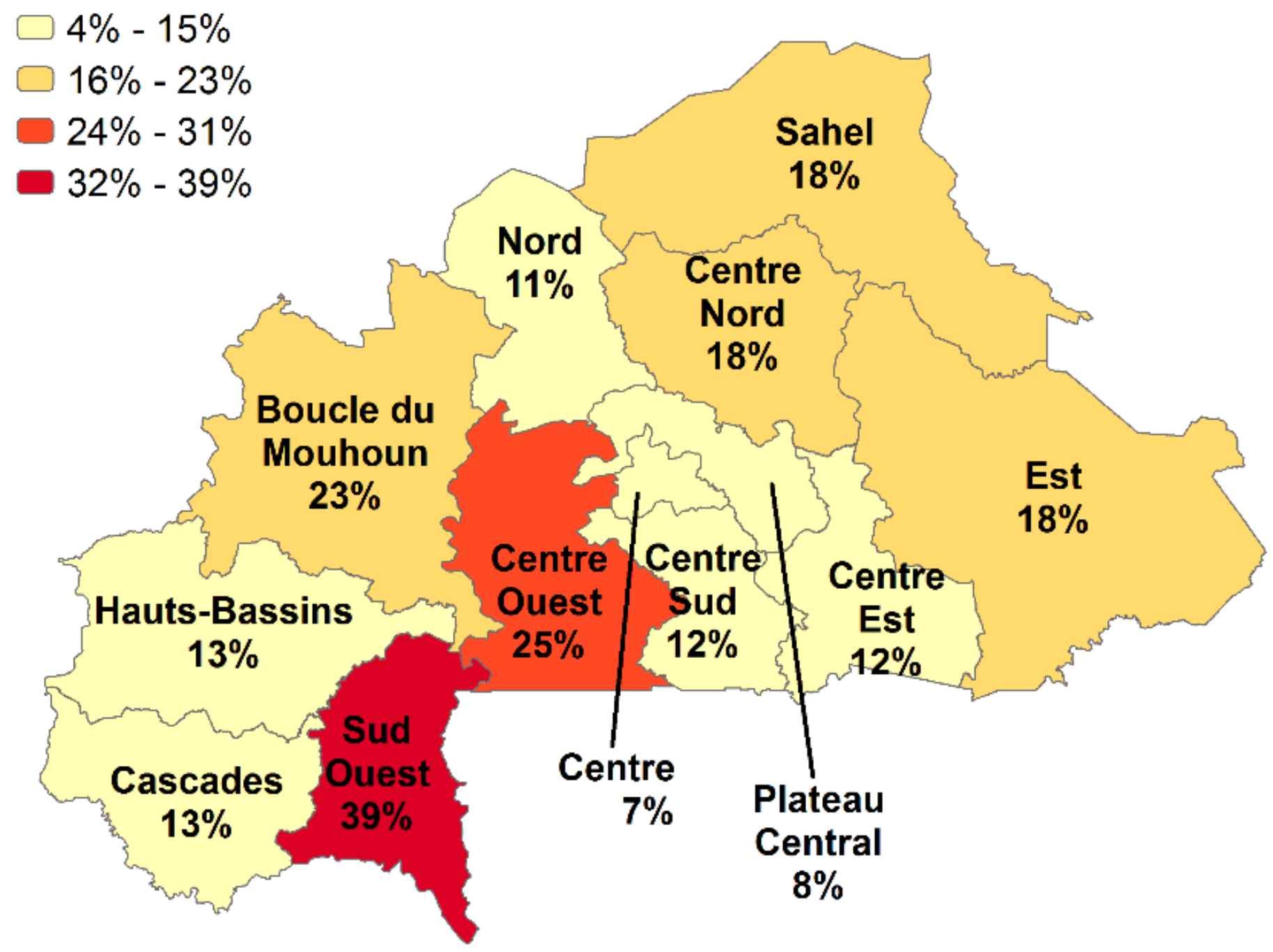

Figure 1

Percentage of children age 6-59 months who tested positive for malaria by microscopy 